IZA DP No. 6746

Stepping Stones versus Dead End Jobs: Exits from Temporary Contracts in Italy after the 2003 Reform

Giovanni S. F. Bruno

Floro E. Caroleo

Orietta Dessy

July 2012 


\title{
Stepping Stones versus Dead End Jobs: Exits from Temporary Contracts in Italy after the 2003 Reform
}

\author{
Giovanni S. F. Bruno \\ Bocconi University, Milan \\ Floro E. Caroleo \\ University of Naples Parthenope, \\ CRISEI and IZA \\ Orietta Dessy \\ Catholic University of the Sacred Heart, Milan
}

Discussion Paper No. 6746
July 2012

IZA

P.O. Box 7240

53072 Bonn

Germany

Phone: +49-228-3894-0

Fax: +49-228-3894-180

E-mail: iza@iza.org

Any opinions expressed here are those of the author(s) and not those of IZA. Research published in this series may include views on policy, but the institute itself takes no institutional policy positions.

The Institute for the Study of Labor (IZA) in Bonn is a local and virtual international research center and a place of communication between science, politics and business. IZA is an independent nonprofit organization supported by Deutsche Post Foundation. The center is associated with the University of Bonn and offers a stimulating research environment through its international network, workshops and conferences, data service, project support, research visits and doctoral program. IZA engages in (i) original and internationally competitive research in all fields of labor economics, (ii) development of policy concepts, and (iii) dissemination of research results and concepts to the interested public.

IZA Discussion Papers often represent preliminary work and are circulated to encourage discussion. Citation of such a paper should account for its provisional character. A revised version may be available directly from the author. 


\section{ABSTRACT \\ Stepping Stones versus Dead End Jobs: Exits from Temporary Contracts in Italy after the 2003 Reform*}

In this paper we study labor market transitions out of temporary jobs in Italy focussing on an interesting period of the Italian recent history: the one immediately following the last labor market reform aimed at flexibilizing and liberalizing the Italian labor market by a widespread use of temporary work arrangements in 2003, and immediately preceding the economic downturn starting in the second half of 2007. The data-set used is the 2004-2007 IT-SILC individual panel. We apply a discrete-time duration analysis and estimate a competing-risk model for assessing to which extent, and for whom, starting a temporary job after 2004 results within a 3-years span in a stepping stone to permanent employment rather than a dead end out of the labor market or in precarious jobs. We find that temporary contracts have a positive impact only on men's transitions to permanent employment. School leavers, workers in the South, as well as women, are instead rather penalized after a temporary job. They have an higher probability to remain trapped in temporary contracts than men and an higher probability of exiting the labour market. In particular, school leavers entering the labour market with a temporary contract experience relatively high exit-rates to non-employment just after the first year of the contract.

JEL Classification: J24, C41, C33, C35, J6

Keywords: mixed multinomial logit, discrete duration data, temporary jobs

Corresponding author:

Floro Ernesto Caroleo

Department of Economic Studies "S.Vinci" and CRISEI

University of Naples "Parthenope"

Via Medina 40

80133 Naples

Italy

E-mail: caroleo@uniparthenope.it

\footnotetext{
*We are grateful to participants at the AISSEC 2011 (Macerata) conference, the University of Naples Parthenope September 2011 workshop, the AIEL 2011 (Milan) conference and the Catholic University of the Sacred Hearth of Piacenza May 2012 workshop for helpful comments and suggestions. We also thank L. Campiglio for useful discussions, and F. Pastore and D. Fiorillo for their initial contributions to the project.
} 


\section{Introduction}

Young people, during their school to work transition, face a problem of gap of work experience. In fact, despite ever increasing educational attainment, they lack the other two components of human capital: generic and job-specific work experience. In order to fill this gap, they carry out a searching strategy by which they move among different labour market statuses in search for the best job-worker match. However, the process of transition is a complex phenomenon with strong elements of rigidity concerning the institutions (school, training and university systems, labour agencies), the norms and contracts regulating the labour market, uncertainty and errors of judgment (Caroleo and Pastore 2009).

To help young people to smooth school-to-work transitions, every country has provided a mix of policy instruments reaching different outcomes. We can sum up these instruments into two groups: policies that, considering the need of firms to minimize the labour costs, aim at introducing different degrees and types of labour market flexibility, and policies that, considering the need of new entrants to adequate their human capital, adopt training programs and labour market active policies or reforms of their education and training system.

In the last decades, in particular, the economic and political debate (OECD 1994) has focused on temporary contracts as a way to increase labour market flexibility mainly in those European countries characterized by an excessive employment protection regulation or that need to speed up the transition process towards a market economy. In response to this concern, several countries have liberalized the rules regulating temporary employment (OECD 2002). Taking a look at the data, Fig. 1 shows that in the OECD area the differences in the share of temporary jobs in total dependent employment are large, ranging in 2010 from 3,1 of Estonia to 23,9 of Spain. However, looking at the percentage variation from 2000 to 2010 (fig. 2) we can see that countries increasing the share are mostly East European in transition economies (Russia Federation, Poland, Slovenia, Hungary), and Mediterranean (Italy, Portugal) and Central European countries (Germany, Netherlands) that, starting from the '90s, have implemented reforms introducing more flexibility in the labour market. On the other hand, even if during the decade Spain (because of the several reforms to attenuate the use this type of contracts) and Turkey have reduced the share of temporary job, they have continued to be among the countries with the highest one.

Most importantly, temporary employment has become the principal way by which youth enter the labour market (OECD 2008). In fact, especially in countries where the employment protection legislation is particularly strict, temporary work has been used to increase entry and exit flexibility at the margin, namely for the new entrants (Ochel, 2009, Boeri and Garibaldi 2007). As a consequence of these two tier strategies, in most cases in 2010 more than one out of two youth employed have temporary jobs (fig. 3 and 4 ).

In this paper we analyze the case of Italy, where the reforms started in the '90s (Treu Law -law 196/1997-, D. Lgs n. 368 /06-09-2001, and Biagi Law -law 30/2003-) have enormously increased the 
probability to be employed in a temporary work. We provide new evidence on job transitions of Italian employees working with temporary contracts -a large portion of which consists of young people, mostly school-leavers, and women- from a so far unexplored source of data. The recently available IT-SILC 2004-2007 panel covers a 'golden' period for an empirical assessment of the consequences of the above reforms for at least three reasons: 1) it covers the years immediately following the last, 2003 reform, for which to the best of our knowledge there is no evidence in the literature; 2) it allows us to stop our analysis before the 2008 economic downturn, so that our results can be interpreted only in terms of effectiveness of the reforms, not being yet contaminated by the negative extra-consequences of the structural trend; 3) it follows the same individuals for at most 4 years, a reasonable time-span for expecting that a person starting a temporary job might have concluded her transition to a stable job.

It must be noted that in the absence of homogeneous pre-reform data we cannot pursue, strictly speaking, an evaluation of policy exercise. Our econometric analysis has instead a simple descriptive intent at this stage. We aim at estimating the impact of a number of economic variables of interest on the durations in temporary employment over a relatively homogeneous post-reform time-span. To be concrete, we estimate a discrete-time competing risk model with two alternative exit-states for a spell in temporary employment: permanent employment or non-employment. The estimation of this model is meant to help answering the following research questions: After the recent attempts to flexibilize the Italian labor market, is temporary employment, and for which categories of workers, indeed a stepping stone to permanent positions? For whom is it instead a dead end out of the labour market or in enduring spells of temporary contracts? In particular, have the weakest segments of the Italian labour market, workers in the South, women and young people, benefited from the upsurge of temporary contracts in the post-reform period?

The paper is organized as follows: in Section 2 we give the state of art in the literature about temporary jobs; Section 3 introduces the econometric strategy suited for our analysis; in Section 4 we give descriptive evidence on our data; Section 5 discusses the results of the model; Section 6 concludes.

\section{The state of art}

The literature on temporary employment shows conflicting theses. According to the mainstream approach, high degree of labour market flexibility, through fixed-term contracts for instance, is the best way to help young people to find their best match in a shorter time, therefore reducing the gap between youth and adult unemployment rates. Clark and Summers (1982) and Freeman and Wise (1982) first suggested that labour turnover is a tool for youth to become adults (see also Rees, 1986; Topel and Ward, 1992). The basic argument is that any labour market experience is better than not working. Temporary jobs allow young people to attain specific human capital (work experience) ${ }^{1}$

\footnotetext{
${ }^{1}$ The argument has been questioned by Becker (1962). In fact, the short time horizon of fixed-term contracts may represent a strong disincentive for young people to invest in job specific competences for both the employer and the
} 
together with the acquisition of firm-specific social capital (relational networks and therefore easier access to the information on vacancies). This view is also based on the hypothesis that long-term unemployment is generally caused by low labour turnover causing in turn state dependence: the longer people stay unemployed, the longer they remain unemployed ${ }^{2}$. In other words, temporary jobs provide a springboard opportunity for young people (stepping stone effect) to the permanent job. Besides, they guarantee lower entry wages and allow firms to form buffer stocks of works reducing hiring, firing and dismissal costs. It might be a probation instrument for firms (Loh, 1994; Wang and Weiss, 1998; Portugal and Varejäo, 2010), and a way for young people to signal their skills and motivation to employers (Booth et al., 2002). Finally, this type of flexibility is less expensive for the public finances than other policy alternatives such as active labour policy or training programs.

However, a widely debated issue is whether temporary jobs are actually a springboard or a stepping stone to permanent work, without causing a long-lasting wage penalty (Pavopoulos, 2009; Barbieri and Cutilli, 2009) or a dead end. In fact, temporary work often becomes a low-pay trap as young people tend to accept low pay jobs and, instead of accumulating work experience to find later high pay-high quality jobs, they remain trapped for many years or also for the rest of their lives.

The evaluation of the stepping stone or of the dead end effect is essentially an empirical issue and needs longitudinal data with similar characteristics to be answered. The available evidence is mixed up. The springboard effect is confirmed in almost all cases but in some studies on the USA (Heinrich et al., 2009; Hotchkiss, 1999; Autor and Houseman, 2005; Addison and Surfield, 2009). The size of the impact, on the other hand, differs hugely across European countries. Cross-country comparative research shows that the effect of entering the labour market trough a temporary contract on the probability to get a permanent job is in general rather weak (O'Higgins, 2010; D'Addio and Rosholm, 2005), underlining that the differences depend on the labour market regimes (Righi and Sciulli, 2009; Scherer, 1999; Garrouste and Loi, 2011; Caroleo and Pastore, 2007) as well as on the regulation mix of the contracts considered, that is to say their length (Gagliarducci, 2005; Antoni and Jahn, 2009), whether they include formal or informal training (Brauns et al., 1999; Contini et al., 2004), whether they are based on financial incentives (Booth et al., 2002), and finally on the diffusion of the Temporary Work Agencies (Ichino et al., 2007; Nunziata and Staffolani, 2007; Amuedo-Dorantes et al., 2008) and/or of policies of temporary help work for unemployed job seekers (Kvasnicka, 2008) ${ }^{3}$.

As said before, the stepping stone or dead end effects are diversified across the European countries. Booth et al. (2002) find that temporary jobs in the UK are substantially bad jobs with wage penalties (Pavlopoulos, 2009) and have scarring effects on future job careers, especially for men. In the AngloSaxon countries (see for the USA Autor, 2001) where the contractual flexibility is very high, temporary

employee. Therefore fixed-term contracts might be seen as a solution only to reduce the gap in generic, but not job specific work experience (see also Caroleo and Pastore 2009).

${ }^{2}$ According to Heckman and Borjas (1980) and Heckman and Singer (1984), however, the hypothesis of state dependence is not supported by empirical evidence.

${ }^{3}$ Nonetheless, it is questionable whether temporary work is a good substitute for general training or active labour market policy (ALMP) (Caroleo 2012). 
(occasional or seasonal) jobs are done by less motivated and less skilled workers. In the case of NorthCentre European countries, a positive stepping stone effect is confirmed (see Holmlund and Storrie, 2002; Hartman et al., 2010 for Sweden; Verhofstadt and Goebel, 2008 for the Flemish region; Zijl et al.,2004 for Netherlands; Hagen, 2003 for Germany). In these countries, temporary contracts are neither the only policy to speed up the school to work transition nor they are used in a massive way. These are rather seen by firms and workers as a tool to tackle adverse macroeconomic shocks and not to make more flexible the labour market.

On the other hand, there is a general consensus in asserting the null effect on reducing the total unemployment or the duration of school to work transition (Quintini et al. 2007), and in deepening the adverse effect on particular groups of workers, in the South-Mediterranean countries where in the last decades two tier reforms have been implemented with the growing use of temporary contracts. Blanchard and Landier (2002) show that in France the two tier reform has raised the worker turnover and worsened the welfare of young workers. Magnac (2000) finds also a strong gender effect. Dolado et al. (2002) find that in a segmented labour market like in Spain, the positive effect on labour turnover, lower unemployment duration and lower firing costs of temporary contracts has been offset by negative consequences such as lower investment in human capital, higher wage pressure (Bentolilla e Dolado, 1994), a more unequal distribution of unemployment duration, lower labour mobility and fertility rates and larger wage dispersion.

On the whole, and in these countries with particular intensity, temporary contracts have perverse effects in terms of efficiency and equity. They are held disproportionately by women, younger people, and less educated workers (Quintini and Martin, 2006; OECD, 2002). Workers starting with a temporary contract tend to be trapped in temporary employment relationships (Alba-Ramirez, 1998). Besides, the stepping stone effect towards permanent employment decreases if temporary jobs are repeated (Garcìa-Pérez and Muñoz-Bullòn, 2007). Too often short-term work causes precariousness of labour market experiences (Güell and Petrongolo, 2007; Harslof, 2003). It tends to be paid less than a permanent job and the wage gap tends to be permanent (Barbieri and Cutilli, 2009); sometimes temporary workers have a harder access to training as well as to benefits like paid vacations, sickness leave, unemployment insurance. They are also less satisfied with their jobs and more often report inflexible work schedules and monotonous tasks (Barbieri and Scherer, 2009) ${ }^{4}$.

Italy is another typical case where the two tier reform has been adopted. As a consequence, in 2010 almost one out of two young workers has a temporary contract, and in the last decade the increase of the share has been one of the highest in the OECD area (Fig. 4). Several researchers have tried to estimate the effect of the reform of the labour market using different data sets and econometric methodologies. Also in this case the results are mixed, even if the stepping stone effect is rather weak for particular groups of workers.

\footnotetext{
${ }^{4}$ Portugal and Varejäo (2010), as an exception to the view that in these countries there is a stigma effect for part-time workers, that is not having been selected for the primary labour market is interpreted as a negative signal by potential future employers, find on the contrary that in Portugal this type of contracts are used as a screening device by firms.
} 
A number of studies use the panel survey of individual work histories drawn by WHIP (Work Histories Italian Panel), which is based on INPS (Istituto Nazionale di Previdenza Sociale, Social Security Institute) administrative archives. With these data Elia (2010) performs a duration analysis estimating a standard proportional hazard Cox model. He finds that workers entering the labour market with a short-term contract are able to convert it in a permanent contract after a very long period. More skilled workers have lower conversion rates which could be explained by the tendency of the firms to extend the probation and screening process for them. Gender discrimination does not seem to affect the transition probability too much. Furthermore, the use of temporary contracts seem to affect mostly the youngest cohorts of workers, in terms of both incidence and lower chances of exiting into permanent employment ${ }^{5}$.

Berton et al. (2011) estimate dynamic multinomial logit models for transitions from different temporary contract arrangements to permanent jobs, finding that, although on the whole they have a port of entry effect, training contracts are the best port of entry to permanent employment, while free-lance contracts are the worst. However, they also observe that, due to the existence of strong state dependence, there is a tendency towards permanent precariousness, particularly for young people, with new entrants becoming trapped in repeated short-term contracts.

The Berton et al. (2011) paper highlights an element already underlined in our introduction, namely temporary workers, to augment the probability to get a permanent job, not only should be more educated but they also need some form of on the job training experience in order to rise their work competence (see also Gagliarducci, 2005).

In line with this argument Cappellari et al. (2011), employing a difference in difference set-up on a panel data on Italian firms derived from the Excelsior data-base, a survey conducted by Unioncamere (the Association of Italian Chambers of Commerce), show that fixed term contracts are not an efficient tool for the firms as they are used to substitute temporary employees with permanent ones and reduce capital intensity, generating productivity loss. On the other hand, apprenticeship contracts increase job turnover and induce the substitution of external staff with firms' apprentices, with an overall productivity enhancing effect.

A number of studies find a positive, even if weak, stepping stone effect. Barbieri and Sestito (2008) adopt a propensity score matching methodology to the Labour Force Surveys (LFS) to show that workers starting with a temporary job augment of $30 \%$ the probability to get a satisfactory employment after one year. Females, adult people and who lives in the low unemployment regions have the highest gains. Gagliarducci (2005) applies multiple-spell duration techniques to ILFI 1997 survey (Indagine Longitudinale sulle Famiglie Italiane) to prove a positive effect of temporary employment on

\footnotetext{
${ }^{5}$ WHIP data suffer of the disadvantage of missing relevant information about individuals, such as the level of education and the year of exit from school, not allowing to analyze young entrants behavior in the labour market. Moreover, it is not known whether, once exiting the WHIP, people actually become unemployed or simply exit the state of employee in the private sector therefore becoming employed in the public sector, or self-employed and also in this case it needs strong assumptions.
} 
the chances of finding permanent employment, although the repeated temporary jobs, especially with interruptions, tend to hinder the transition to permanent employment.

On the 2000, 2002, and 2004 waves of the Survey of Italian Households' Income and Wealth (SHIW) conducted by the Bank of Italy, Picchio (2008) estimates different specifications of dynamic probit models for transitions to permanent employment, finding that temporary contracts have a 2 years' stepping stone effect. Nevertheless, since the survey is bi-annual, the results are strongly affected needing ad hoc assumptions.

Ichino et al. (2007) find a springboard effect of workers starting a temporary job trough Temporary Work Agencies. They use an ad hoc data base for two Italian regions adopting sensitivity analysis on matching estimators. However results don't seem robust for the Southern region.

Barbieri and Scherer (2009) trough a (continuous time) competing risk piecewise constant exponential model applied on the data from 1997, 1999, 2001, 2003 and 2005 ILFI surveys, estimate the probability of the transition into stable employment having started with a temporary job. They find in general a scant stepping stone effect with strong elements of discrimination for youth, women, less educated and workers living in the Southern regions. These are likely to remain trapped in the precariousness and underpaid with respect to equivalent permanent positions, all job and individual characteristics being equal (see also Barbieri and Cutilli, 2009).

Summing up, the research on the stepping stone effect shows that temporary employment in principle increases the probability of finding permanent work, but in a rigid labour market only few are winners. The concrete risk is that less favored workers (especially youth, women and people living in the less favored regions) fall into a dead-end relegating them, sometimes for a very long period of time, in working circuits characterized by temporary and/or part-time jobs, informal sectors without guarantees, long-term unemployment, with highly negative social effects.

Our new evidence, presented in this paper, shows that the most recent reforms carried out in Italy, although increasing the use of temporary contracts, unfortunately have not yet succeeded in improving the above results.

\section{The econometric model}

We estimate a discrete-time duration model for temporary employment, $T E$, with two competing exit states: permanent employment, PE, and non-employment, NE. The structure of the model is essentially the same as that estimated by D'Addio and Rosholm (2005) on the ECHP data-base over the years 1994-1999, with the difference that we estimate it on the IT-SILC data-base for the years 2004-2007 and explicitly take school leavers into consideration, as explained in Subsection 4.3.

Estimation is carried out through a multinomial model on suitably reorganized data (see Jenkins, 2005). We start from a random sample of $N$ individuals observed over at most $T$ time periods. In what follows we focus on a generic individual $i=1, \ldots, N$, whose spell begins at date $t=0$. Time 
spells are discrete and, as such, are indicated by $t=1, \ldots, T$.

Let $T_{i}^{j}$ denote the random duration in $T E$ for individual $i$ with exit $j=N E, P E$, so that if exit occurs over the year $(t, t+1], T_{i}^{j}=t$. In other words, $T_{i}^{j}$ is the number of years in $T E$, not including the year in which exit occurs. Clearly, $T_{i}^{P E}$ and $T_{i}^{N E}$ are both latent variables, only $T_{i} \equiv \min \left(T_{i}^{P E}, T_{i}^{N E}\right)$ is observable, and possibly censored if falling outside the individual observation period as explained below. Given this, the discrete hazard function, conditional on a vector of explanatory variables $z$, for an arbitrary spell $t=\tau \geq 1$, is

$$
\begin{aligned}
h_{i \tau} & \equiv \operatorname{Pr}\left(T_{i}=\tau \mid T_{i} \geq \tau, z_{i \tau}\right) \\
& =\operatorname{Pr}\left(T_{i}^{P E}=\tau \mid T_{i} \geq \tau, z_{i \tau}\right)+\operatorname{Pr}\left(T_{i}^{N E}=\tau \mid T_{i} \geq \tau, z_{i \tau}\right) \\
& \equiv h_{i \tau}^{P E}+h_{i \tau}^{N E}
\end{aligned}
$$

with a corresponding survivor function given by

$$
S_{i \tau} \equiv \operatorname{Pr}\left(T_{i}>\tau \mid z_{i \tau}\right)=\prod_{t=1}^{\tau}\left(1-h_{i t}\right)
$$

Therefore,

$$
\operatorname{Pr}\left(T_{i}=\tau \mid z_{i \tau}\right)=\operatorname{Pr}\left(T_{i}^{P E}=\tau \mid z_{i \tau}\right)+\operatorname{Pr}\left(T_{i}^{N E}=\tau \mid z_{i \tau}\right)=h_{i \tau} S_{i \tau-1} .
$$

An important point, to which we refer back below, when writing the likelihood function, regards the formula of $h_{i 1}$ : since for all individuals in the sample $T_{i} \geq 1$,

$$
h_{i 1}=\operatorname{Pr}\left(T_{i}=1 \mid z_{i 1}\right) .
$$

Now, let $t_{i}$ indicate the length of the observed spell in $T E$ for individual $i$. His/her observation period is so $t=1, \ldots, t_{i}$. As in D'Addio and Rosholm (2005), we exclude all individuals with leftcensored spells from the estimation sample, so that, according to the definition of D'Addio and Rosholm (2002), all the spells in progress at the beginning of the observation period and with an unknown origin date are removed from the sample. This boils down to removing all individuals with a temporary contract at time $t=1$. As a result, each individual in the estimation sample can be found in one of three mutually exclusive states:

PE exit to permanent employment: $T_{i}^{P E}=t_{i}$;

NE exit to not-employment: $T_{i}^{N E}=t_{i}$;

TE staying in temporary employment: $T_{i}>t_{i}$.

While $N E$ and $P E$ are cases of completed spells, $T E$ is a case of right-censored spell. Left-censored 
spells are excluded. To indicate each state, we define the following binary variables

$$
\begin{aligned}
& \delta_{i} \equiv\left\{\begin{array}{lll}
1 & \text { if } & T_{i}=t_{i}, \\
0 & \text { if } & T_{i}>t_{i},
\end{array},\right. \\
& \delta_{i}^{j} \equiv\left\{\begin{array}{ccc}
1 & \text { if } & T_{i}^{j}=t_{i} \\
0 & \text { if } & T_{i}^{l}=t_{i} \text { or } T_{i}>t_{i}
\end{array},\right.
\end{aligned}
$$

with $j \neq l=N E, P E$. Clearly, $\delta_{i}^{N E}+\delta_{i}^{P E}=\delta_{i}$.

The explanatory variables in the conditioning set enter the model through the linear index function $z_{i t}^{\prime} \theta_{j}$. Following a common practice in the econometric literature on duration (Jenkins 2005), we specify $z_{i t}^{\prime} \theta_{j}$ as

$$
z_{i t}^{\prime} \theta_{j} \equiv D_{i t}^{\prime} \gamma_{j}+x_{i t}^{\prime} \beta_{j}
$$

where $D_{i t}$ is a vector of dummy variables indicating durations $t=1, \ldots, t_{i}$ for each individual record, and so captures duration dependence in the hazard function; $x_{i t}$ contains the economic variables of interest, described in Subsection 4.3.

With this in mind and given Equations (1) and (2), we can write the contribution of an individual $i=1, \ldots, N$ to the likelihood function when $t_{i}>1$ as

$$
\begin{aligned}
L_{i}\left(\theta \mid z_{i t}\right)= & \operatorname{Pr}\left(T_{i}^{P E}=t_{i} \mid z_{i}\right)^{\delta_{i}^{P E}} \operatorname{Pr}\left(T_{i}^{N E}=t_{i} \mid z_{i}\right)^{\delta_{i}-\delta_{i}^{P E}} \operatorname{Pr}\left(T_{i}>t_{i} \mid z_{i}\right)^{1-\delta_{i}} \\
= & {\left[h_{i t_{i}}^{P E} \prod_{t=1}^{t_{i}-1}\left(1-h_{i t}^{P E}-h_{i t}^{N E}\right)\right]^{\delta_{i}^{P E}}\left[\prod_{t=1}^{t_{i}}\left(1-h_{i t}^{P E}-h_{i t}^{N E}\right)\right]^{1-\delta_{i}} } \\
& {\left[h_{i t_{i}}^{N E} \prod_{t=1}^{t_{i}-1}\left(1-h_{i t}^{P E}-h_{i t}^{N E}\right)\right]^{\delta_{i}-\delta_{i}^{P E}}\left[\prod_{t=1}^{t_{i}}\left(1-h_{i t}^{P E}-h_{i t}^{N E}\right)\right]^{\delta_{1}} } \\
= & \left(h_{i t_{i}}^{P E}\right)^{\delta_{i}^{P E}}\left(h_{i t_{i}}^{N E}\right)^{\delta_{i}-\delta_{i}^{P E}}\left[\prod_{t=1}^{t_{i}-1}\left(1-h_{i t}^{P E}-h_{i t}^{N E}\right)\right]^{1-\delta_{i}}\left(1-h_{i t_{i}}^{P E}-h_{i t_{i}}^{N E}\right) \\
= & \left(h_{i t_{i}}^{P E}\right)^{\delta_{i}^{P E}}\left(h_{i t_{i}}^{N E}\right)^{\delta_{i}-\delta_{i}^{P E}}\left(1-h_{i t_{i}}^{P E}-h_{i t_{i}}^{N E}\right)^{1-\delta_{i}} \prod_{t=1}^{t_{i}-1}\left(1-h_{i t}^{P E}-h_{i t}^{N E}\right) .
\end{aligned}
$$

Given Equation 3, the individual likelihood function contribution when $t_{i} \equiv 1$ reduces to

$$
L_{i}\left(\theta \mid z_{i t}\right)=\left(h_{i 1}^{P E}\right)^{\delta_{i}^{P E}}\left(h_{i 1}^{N E}\right)^{\delta_{i}-\delta_{i}^{P E}}\left(1-h_{i 1}^{P E}-h_{i 1}^{N E}\right)^{1-\delta_{i}} .
$$

To make $L\left(\theta \mid z_{i t}\right)$ operational, we maintain a logistic distribution for $h_{i t}^{j}, j=N E, P E, i=1, \ldots, N$, 
$t=1, \ldots, t_{i}:$

$$
h_{i t}^{j}=\frac{\exp \left(z_{i t}^{\prime} \theta_{j}\right)}{1+\exp \left(z_{i t}^{\prime} \theta_{P E}\right)+\exp \left(z_{i t}^{\prime} \theta_{N E}\right)} .
$$

Note that the hazard function for the $T E$ category is identified by $h_{i t}^{N E}$ and $h_{i t}^{P E}$ :

$$
h_{i t}^{T E}=\frac{1}{1+\exp \left(z_{i t}^{\prime} \theta_{P E}\right)+\exp \left(z_{i t}^{\prime} \theta_{N E}\right)} .
$$

It is thereby apparent that $L_{i}\left(\theta \mid z_{i t}\right)$ is the likelihood function for a particular multinomial model (Jenkins, 2005), one such that:

- observations are organized first by individuals, $i=1, \ldots, N$, and then by time within individuals, $t=1, \ldots, t_{i}$, as in a standard (unbalanced) panel data set with sample size $n=\sum_{i=1}^{N} t_{i}$;

- for each person-period observation $(i, t)$, there are three possible mutually exclusive "choice" categories available: $T E, P E$ or $N E$, with the former being the base category;

- if $t_{i}>1$, the categories $P E$ and $N E$ can be observed only at the end of the observed spell, that is at observation $\left(i, t_{i}\right)$.

- if $t_{i}>1$, the first $t_{i}-1$ observations are all $T E$.

Eventually, the log-likelihood function (LF) to be maximized is

$$
\log L(\theta \mid z) \equiv \sum_{i=1}^{N} \log L_{i}\left(\theta \mid z_{i t}\right) .
$$

To be precise, the LF in Equation (4) is to be thought of as a partial LF, rather than a fully specified conditional LF, and this for two reasons. First, most of the variables in $z$ are actually predetermined, as opposed to strictly exogenous. Second, in computing standard errors we allow cluster correlation in the error terms. Maximization of $\log L(\theta \mid z)$ will nonetheless produce consistent coefficient and average marginal effect estimates under random samplings of individuals and absence of unobserved heterogeneity. A discussion on the issue of unobserved heterogeneity in the context of our data is postponed to Section 5 .

The coefficient $\theta_{k}^{j}$ on a given variable $z_{k}$ is the marginal effect of that variable on the log odds ratio:

$$
\theta_{k}^{j}=\frac{\partial}{\partial z_{i t, k}}\left(\log \frac{h_{i t}^{j}}{h_{i t}^{N E}}\right),
$$

as such its sign is informative on the relative impact of $z_{k}$ on $h_{i t}^{j}$ compared to $h_{i t}^{N E}$. The marginal 
effect of $z_{k}$ on $h_{i t}^{j}, \partial h_{i t}^{j} / \partial z_{i t, k}$, is evidently easier to interpret and is given by

$$
\frac{\partial h_{i t}^{j}}{\partial z_{i t, k}}=h_{i t}^{j}\left[\theta_{j, k}-\left(\theta_{N E, k} h_{i t}^{N E}+\theta_{P E, k} h_{i t}^{P E}\right)\right] .
$$

The derivation of the log-likelihood function for our data, with the required regularity conditions, is detailed in Appendix 1.

\section{The data}

The data-set used in this study is the Italian part of the EU-SILC 2004-2007 panel, the so-called ITSILC, in its longitudinal version. Each year a representative sample of households is drawn from the population, and all their current members (13,000 on average every year) are eligible to be surveyed and followed up for four consecutive years ${ }^{6}$. Women are slightly more represented than men in IT-SILC data, as they are the $52 \%$ of the sample on average in each wave.

The variable that defines the three mutually exclusive states of our econometric model is constructed as follows. The TE and PE statuses are taken from the variable type of contract, which explicitly reveals whether or not employment will be eventually time-limited under an agreement. The question, addressed only to employees, refers to the main job hold over the year, i. e. the one with the greatest number of hours usually worked. In Italy, during the period considered in our study, the IT-SILC TE category aggregates the typical temporary contractual arrangements existing since the '60s in the Italian the labor market (such as seasonal jobs, training and apprenticeship), and that have been more and more liberalized since 2001, and the new fixed-term contractual arrangements introduced between 1997 and 2003 (the so-called autonomous or free-lance contracts) ${ }^{7}$.

Our empirical analysis is meant to assess whether people starting a TE in our period of observation end up either in a positive outcome, i.e. a PE position, or in a negative outcome, i.e. NE. As in previous studies, in the NE status we pool together unemployed and people out of the labor market. The information is taken from an yearly variable that collects the self-defined economic status perceived by individuals during the period of reference. In the category of NE we therefore include people unemployed, in retirement or early retirement, fulfilling domestic tasks and care responsibilities, or inactive for other unspecified reasons ${ }^{8}$.

Persons permanently disabled and/or unfit to work, as well as in compulsory military community or service, are excluded from the sample, as well as employees who don't report the contract length because self-employed. We also do not consider in our study immigrants as their working careers are

\footnotetext{
${ }^{6}$ Details of the survey are reported in Appendix 1.

${ }^{7}$ See Mandrone and Marocco (2012) and GianMatteo, Mandrone and Tancioni (2012) for an updated analysis on disaggregated contractual arrangements from ISFOL-plus 2005-2008 and 2008-2010 data.

${ }^{8}$ This will be the variable used also for identifying school-leavers, as will be explained later on, since student is one of the possible self-declared statuses.
} 
well known to be determined according to very different mechanisms with respect to natives, and focus on individuals aged between 16 and 66 in 2004.

In the next subsection we give some descriptive evidence on transitions from TE emerging from our updated panel. Subsection 4.2 describes the sample that will be used for estimating our model, explaining in detail how it has been constructed. In Subsection 4.3 we motivate the selection of the variables used for explaining the observed transitions, also providing some summary statistics.

\subsection{Descriptive evidence}

We present in Table 1 some recent evidence for Italy, that emerges from our updated 2004-2007 ITSILC data. For the whole sample we show average year-to-year transitions from TE to PE and NE. The table evidences the two relevant dimensions of interest for our analysis: gender and age differences. Overall we can see that there is a strong stability in the TE status from one year to the next: about $52 \%$ of our sample does not exit TE, the percentage being higher for women, and increasing with age (from zero to $10 \%$ points gap with respect to men when after 40). Overall the difference between age cohorts is not very strong, even though we observe that at the beginning, between the first and the second group of age, the percentage of TE increases of $4 \%$ points whereas from the second to the third group of age it decreases of $1 \%$ point.

A $31 \%$ portion of the sample consists of people who successfully move from TE to PE. Also for the positive outcome we do not see any hard age-effect, whereas the gender difference is pronounced: from 4 to $9 \%$ women less than men transit to a PE in one year.

Concerning the NE outcome, we observe a less pronounced gender effect (3\%) and a stronger age effect: in the youngest cohort $18 \%$ of individuals transit to NE, the percentage decreasing to $14 \%$ for people aged between 26 and 39. The highest values for the third cohort can be explained with the fact that the NE category includes also people retired.

Summing up: overall TE seems to act as a stepping stone, although less so for women and young people. Our descriptive evidence confirms some of the results found in the literature for pre-2004 data, showing that the recent policies have not yet completely reached their goals, especially in terms of supporting stability among women and young people.

The foregoing picture is only partial, of course, illustrating what happens in the short time of yearto-year transitions and unconditionally. The econometric analysis aims to offer a richer explanation of the transition probabilities, following workers over their whole observation period and conditioning on a number of supposedly relevant explanatory variables.

\subsection{The estimation sample}

Some data restructuring is required for estimation along the following three steps. 
First, as explained in Section 3, we need discriminating between entrants in TE and left-censored spells. To this purpose, we use the inflow information available, so that an individual is classified as an entrant in TE if, and only if, in TE in the second record, but not in the first. We only keep individuals meeting this requirement, and so the first record is lost for any individual kept. After some other minor adjustment we are left with 1,786 records and 1,185 individuals.

Second, the information in the year when the individual exits to NE or PE is used only to determine the last year of TE for any completed spell and does not contribute to estimation. This further reduces the number of observations to 1,460 records, but leaves the number of individuals unchanged.

Finally, cleaning up the data for missing values in the explanatory variables leaves us with the definitive estimation sample of 1,440 observations and 1,172 individuals.

Table 2 shows the patterns of duration in the final sample: $79 \%$ individuals are observed for one period, $18 \%$ for 2 periods and only $3 \%$ are observed for three periods. It is, therefore, apparent that singletons are predominant in the estimation sample, which will prevent attempts of controlling for unobserved heterogeneity, as explained in Section 5. As to the age and gender characteristics of the estimation sample: $50 \%$ of individuals are less than 30 years old and more than $75 \%$ are less the 40 ; and female workers are slightly more numerous than males, contributing with $53 \%$ of the spells.

\subsection{The explanatory variables}

We condition on individual-specific variables, that can be either time-varying or time constant. We also include time-varying variables at higher levels of aggregation. Summary statistics for the estimation sample are given in Table 3. Below we provide a succinct discussion of all explanatory variables in the model.

Although the first record for any individual kept does not contribute to the estimation sample, we use the first-record information as in D'Addio and Rosholm (2005) to construct indicators of the individual status ahead of starting TE, and include them in the conditioning set. But differently from D'Addio and Rosholm (2005), where the initial state is constrained to be binary: either PE or NE, we explicitly include the status of being student (declared by individuals in the same variable used for defining the NE status and, as such, homogeneous to this information) as a third separate category. In this way we can identify school leavers even though the information on the year of attained highest degree of education (the variable normally used to this purpose in the literature) is missing.

Among personal and family characteristics we consider: sex, age (included non-linearly), region of residence, marital status, health and a dummy that indicates if during the period the person has had a children less than 12 years old.

Women are analyzed separately from men, as in most of the previous literature on the subject, on the view that women's labour market behavior is completely different from men's. Such discrepancy already emerges quite clearly from the descriptive evidence of Subsection 4.1. 
Regions are aggregated into five macro-areas: North-East (17\% of the sample), North-West (23\%), Centre (24\%), South (27\%) and Islands (9\%). These geographical controls are part of our conditioning set since the Italian labor market is well-known to be affected by enormous regional disparities. For this reason, we also control for two regional, time-varying, indicators of the structural economic trend: regional unemployment (for local labor market characteristics) and regional growth (for the cyclical components $^{9}$ ).

From the information on family characteristics available in IT-SILC we have picked out two variables: marital status and the number of children. According to the marital status declared, we distinguish people into two mutually exclusive groups: those who are not married, from those that at the time of the survey either are or have ever been married, therefore including in this category widowed, separated and divorced. This last group represents the majority of our sample, with $53 \%$ of observations. As for the number of children, our dummy children less than 12 is time-constant, indicating whether between 2004 and 2007 the person has ever had a children younger than 12 (33\% of the sample).

The variable health is taken from the auto-declared level of general health. It is included in our model as another important element of observed workers heterogeneity, since it can determine both their labor performance and their on-the-job search activity. So, in the dummy health good we aggregate the medium-high levels reported (very good, good and fair) as opposed to the lower perceived health statuses (bad and very bad), aggregated in the complementary health bad dummy, indeed peculiar to only $3 \%$ of our sample.

Employees' human capital is measured by two variables: experience and maximum level of education. Experience corresponds to the declared number of years in paid jobs. They range between a minimum of 1 year and a maximum of 46 years, with an average of 10 years. The six highest levels of education available in the original data have been aggregated as follows: Education primary includes pre-primary and primary levels of education; Education secondary aggregates people with lower secondary, upper secondary and post-secondary non-tertiary-education levels of education; Education tertiary identifies individuals with a first stage of tertiary education (not leading directly to an advanced research qualification) as well as individuals with a second stage of tertiary education (leading to an advanced research qualification). The majority of individuals in the estimation sample (77\%) is in the Education secondary group, $16 \%$ belong to the Education tertiary group and only $7 \%$ is in Education primary.

As far as regards jobs' characteristics ${ }^{10}$, unfortunately the longitudinal version of IT-SILC misses some useful information, such as the sector of activity, or the firm size. The only one available is

\footnotetext{
${ }^{9}$ Both series are taken from ISTAT's web-site: www.istat.it

${ }^{10}$ In the previous literature for Italy some authors (Gagliarducci (2005), Picchio(2008) and Barbieri and Sherer (2009) on ILFI or SHIW data) deliberately do not include job characteristics in their analyses because correlated with TE. Others (all those working with WHIP data, where individual and family characteristics are not available) consider only job characteristics. We have included instead all the information available as in D'Addio and Rosholm (2005).
} 
occupation, reported according to the ISCO-88 2-digit codes, that we have aggregated into three broad categories, according to the level of skill required: High (29\% of our data), Medium (35\%) or Low $(38 \%)^{11}$.

Besides contract length, another observed characteristic peculiar to the contracts is the distinction between part-time and full-time jobs. Full-time workers are the majority of those starting TE between 2004 and 2007, 74\%. Clearly, working part-time is another way of implementing job flexibility, one that is used for both TE and PE. Therefore, such information is part of our conditioning set.

We have also information about employees' labor income in the IT-SILC longitudinal data. This refers to the income reference period, and consists of the monetary component of the compensation of employees payable in cash by an employer to an employee. Although both gross and net measures are available, we have chosen the employees' net cash, or near cash, income, because income gross is missing for the majority of individuals ${ }^{12}$.

Another variable that is sometimes considered in the literature is a dummy that indicates whether employees have received benefits. The economic rationale, as evidenced by theoretical models, is simple. A person that benefits of unemployment, redundancy, or any other kind of allowances has less incentives for exerting job-search effort, which, in consequence, would bring about a low probability of transition to PE. Since we restrict our focus to people in TE, our benefit dummy clearly excludes unemployment benefits and takes on unity value if over the reference period the individual has received monetary aids for at least one of the following reasons: disability, education, old age and survivor (5\% of the sample). Given this, we find it difficult to determine the sign of this variable's effect on purely theoretical grounds, deeming it as more an empirical matter.

\section{Results}

In this section we discuss the results of the estimation of the econometric model introduced in Section 3. First the estimated marginal effects will be presented, showing the ceteris paribus estimated impact of explanatory variables on the probability of the various transitions, and then the observed and estimated hazards will be presented.

\subsection{The estimated marginal effects}

Table 4 shows the sample-averaged marginal effect estimates for the probability of survival in TE and the hazards out to PE and NE. Results are displayed for the whole sample (columns 1-3) and the two separate subsamples of male (columns 4-6) and female workers (column 7-9).

\footnotetext{
${ }^{11}$ Those occupied in the army forces have been excluded from the sample. Our re-classification of occupations matches the one proposed by Goos et al. (2010) in Tab. 4, with minor modifications as follows: High skills = low-routine-intensity tasks (ISCO 1, 2, 3); Medium skills = medium-routine-intensity tasks (ISCO 4, 5, 6); Low skills = high-routine-intensity tasks (ISCO $7,8,9$ ).

${ }^{12}$ Net is meant from reduction of taxes at source and/or social insurance contributions.
} 
To interpret the results keep in mind that the reference type for the two subsamples is a single worker with no children less than 12 years old, the lowest level of education, in good health, not receiving any benefit and coming from PE, ahead of starting a TE spell with the following characteristics: full-time position in a high-skill job located in the North-East. In the whole subsample the reference worker is a male worker with the foregoing characteristics.

Next we comment the most salient results, focussing on the two subsamples.

1. For both men and women there is clear evidence of duration dependence. Ceteris paribus, the longer the stay in TE, the higher the probability of remaining in TE.

2. As expected, significant regional disparities emerge. For both men and women working in the South increases the probability of being trapped into TE as opposed to exiting to PE or NE.

3. Obtaining a TE position directly after leaving school seems to lower the probability of upgrading to $\mathrm{PE}$, although this effect is mildly significant and emerges at the level of the whole sample only. Nonetheless, we observe that such a negative impact holds through for both men and women.

4. A period of NE, before starting TE, is significantly detrimental on the chances of a PE position only for women. This effect probably drives the same result at the level of the whole sample, where a significant positive effect on the probability of exiting the labor market after TE is also observed.

5. While a status of bad health does not explain men's job transitions, it has a strong negative impact towards exclusion of women from stable positions in the labor market, either keeping them in TE, or pushing them into NE.

6. Family characteristics expectedly affect men differently from women. Having children aged less than 12 years old seems to exert an impact towards keeping parents active in the labour market, on the one hand reducing the men's chances of NE and, on the other, increasing the women's probability of preserving their TE positions.

7. A medium level of education helps in avoiding the NE status, but only for men.

8. For women TE in low-skill occupations is more likely to end up into an exit from the labor market.

9. To the opposite, women having a part-time position are less likely to exit from the labor market, but at the price of a longer permanence in TE.

10. The finding that the hazards to PE and NE are higher not only in regions where growth is higher, but also where unemployment is higher is difficult to explain. D'Addio and Rosholm (2005) find exactly the same result and suggest that when unemployment increases, temporary jobs are the 
first ones to be destroyed by firms, thus generating an increasing outflow from temporary jobs in all directions.

Accommodating unobserved heterogeneity is important in discrete-time duration models, since it permits to relax the assumption of independence from irrelevant alternatives (IIA) maintained by homogeneous multinomial logit models. The nonparametric method suggested by Heckman and Singer (1984), allowing for the presence of discrete individual-specific error components into the specification of the logistic distribution, is by far the most widely used procedure to deal with unobserved heterogeneity in this literature. However, the predominance of singletons (one-year durations in TE) in our estimation sample - accounting as much as $79 \%$ of the spells (Table 2) - clearly prevents us from any attempts in this sense ${ }^{13}$. That said, it is well known that an homogeneous multinomial probit model does not require IIA (see Wooldridge 2010), and as such lends itself as a robust, although computationally expensive itself, alternative to the error components multinomial logit à la Heckman and Singer. For this reason, we have complemented the multinomial logit estimates with estimation of a multinomial probit model, thought of as a robustness check to violations of the IIA assumption. The probit results largely confirm the above findings and are available upon request from the Authors ${ }^{14}$.

\subsection{Estimated hazards, empirical hazards and goodness of fit}

Following Bover et al. (2002), we evaluate the goodness of fit of the model by comparing average hazard estimates from the model to the empirical hazards along several dimensions of interest.

The empirical hazard to PE after $t$ years of TE is obtained as the portion of temporary employees for at least $t$ years that find a permanent contract after $t$ years. The empirical hazard to NE after $t$ years of TE is similarly computed as the portion of temporary employees for at least $t$ years that enter NE after $t$ years.

Tables 5 and 6 show, for the subsamples of men and women respectively, the empirical hazards and average hazard estimates for the two only completed spells observed in our sample, $t=1$ and $t=2$. For each subsample, results are then broken down by regions (North \& Centre vs. South \& Isles) and age (less vs. more than 30 years old). The goodness of fit is quite satisfactory overall, with the hazard estimates that always fall inside the empirical hazard $95 \%$ asymptotic confidence intervals.

Either looking at the empirical or at the estimated hazards, the following patterns seem to emerge quite clearly.

1. For men, one more year in TE markedly increases the probability of finding a permanent position relative to a one-year duration. This holds for all dimensions, excepted South \& Isles, where the increase does not seem so pronounced if measured by the empirical hazards, or even completely

\footnotetext{
${ }^{13}$ Excluding singletons, as for example in Bover et al. (2002), is clearly not feasible here given the large portion of such cases in our estimation sample.

${ }^{14}$ See Bruno, Caroleo and Dessy (2012) for theoretical results on average partial effects in multivariate probit models and further evidence on the IT-SILC data.
} 
offset if measured by the estimated hazards. The opposite occurs in the women subsample, where to a longer duration in TE corresponds a lower probability of finding a permanent contract.

2. The probability that men exit employment after just one year of TE is always smaller than women's, especially women based in South \& Isles.

3. After two years of TE the probability of exiting to NE markedly reduces in both subsamples and for all dimensions.

4. In both subsamples school-leavers show an unstable position in the labour market: after just one year of TE, they have a relatively small exit rate to $\mathrm{PE}$ and a relatively high exit rate to NE.

We conclude therefore that TE contracts of longer duration are stepping stones only for men. They, nonetheless, protect both men and women from unemployment, decreasing for both the exit rate to $\mathrm{NE}$ in 2 years, but this at the expenses for women to remain trapped in precarious jobs. Also for school leavers TE seem to be dead ends, not only in terms of a longer permanence in the TE status, but also of higher exit-rates to NE in the short run.

\section{Conclusions}

In this paper we have used a recent 2004-2007 individual longitudinal data-set to assess empirically whether in the post-reform period the widespread use of temporary contracts has had either a stepping stone or a dead end effect. The estimation of a discrete-time competing risk model essentially confirms some of the existing results found with different methods and data for the previous period.

In particular, we find that temporary contracts have a stepping stone effect only for men. If temporary contracts seem to generally protect from unemployment, this happens at the expense of letting certain categories of employees trapped in precarious jobs, especially women and school leavers. Finally, we also find strong regional effects, since temporary jobs in Southern Italy have a lower probability, compared to the rest of Italy, of ending with a permanent position both in the first and in the second year, and for both sexes.

The analysis carried out in this paper adds new and interesting evidence to the literature. It shows that, about after ten years since the beginning of institutional changes in the Italian labor market, the weak side of the market, as represented by young people, women and workers in the Southern regions, still find difficulties in getting stable jobs. This is, however, not enough to deem these policies as not-effective for at least three important reasons. First, since with the data available we are not able to identify what would have happened in the absence of the reforms, we could not carry out a proper evaluation of policy. Second, monthly information on the length of contracts is missing in the IT-SILC data, which prevented us from focussing on unemployment durations for assessing whether temporary jobs help transitions out of unemployment. In this respect, it seems promising to join the analysis 
of unemployment and temporary employment durations in one general multiple-spells model using appropriate monthly data. Finally, further research on the various temporary contract typologies, distinguishing in particular between the typical and the recently introduced contractual arrangements, would certainly shed more light on the labour-market impact of the new forms of temporary jobs. All of the foregoing issues are part of our undergoing research.

We have also in our research agenda to compare the Italian case with other countries using the EU-SILC data on a longer time-span, which would allow us to identify the performance of temporary contracts over the economic downturn. 


\section{References}

Addison, J. T. and J. S. Christopher (2009), Atypical Work and Employment Continuity, Industrial Relations: A Journal of Economy and Society, Vol. 48, Issue 4: 655-683.

Alba-Ramìrez,A. (1998), How Temporary is Temporary Employment in Spain?, Journal of Labor Research, 19: 695-710.

Amuedo-Dorantes,C., Malo, M. A. and F. Muñoz-Bullòn (2008), The Role of Temporary Help Agency Employment on Temp-to-Perm Transitions, Journal of Labor Research ,Vol. 29, n. 2: 138161.

Antoni, M. and E. J. Jahn (2009), Do changes in regulation affect employment duration in temporary help agencies?, ILR Review, 62(2): 226-251.

Autor, D.H. (2001), Why do Temporary Help Firms Free General Skills Training?, The Quarterly Journal of Economics, 116(4): 1409-1448.

Autor, D.H. and S. Houseman (2005), Do Temporary Help Jobs Improve Labor Market Outcomes for Low-Skill Workers? Evidence from Random Assignments, NBER discussion paper, n. 11743.

Barbieri, G. and P. Sestito (2008), Temporary Workers in Italy: Who Are They and Where They End up, Labour, 22(1): 127-166.

Barbieri, P. and G. Cutilli (2009), Equal Job, Unequal Pay: Fixed term Contracts and Wage Differentials in the Italian Labor Market, Dipartimento di Sociologia e Ricerca Sociale, quaderno n. 45.

Barbieri, P. and S. Scherer (2009), Labour Market Flexibilization and its Consequences in Italy, European Sociological Review, 25(6): 677-692.

Becker, G. S. (1962), Investment in Human Capital: A Theoretical Analysis, The Journal of Political Economy, 70(5): 9-49.

Bentolila, S. and J. Dolado (1994), Labour flexibility and Wages: Lessons from Spain, Economic Policy, 9(18): 53-99.

Berton ,F., Devicienti, F. and L. Pacelli (2011), Are temporary jobs a port of entry into permanent employment? Evidence from matched employer-employee data, International Journal of Manpower, 32 (8): 879-899.

Blanchard, O. and A. Landier (2002), The perverse effects of partial labour market reform: Fixed term contracts in France, The Economic Journal, Vol. 112, Issue 480: F214-F244.

Boeri, T. and P. Garibaldi (2007), Two-tier Reforms of Employment Protection: A Honeymoon Effect?, The Economic Journal, Vol. 117, Issue 521: 357-385.

Booth, A., Francesconi, M. and J. Frank (2002), Temporary jobs: stepping stones or dead ends?, The Economic Journal, Vol. 112, Issue 480: F189-F213.

Bover, O., Arellano, M. and S. Bentolila (2002), Unemployment duration, benefit duration and the business cycle, The Economic Journal, 112, 223-265. 
Brauns, H., Gangl, M. and S. Scherer (1999), Education and unemployment: patterns of labour market entry in France, the United Kingdom and Germany, MZES Working Paper, n. 6.

Bruno, G. S. F., Caroleo F. E. and O. Dessy (2012), Average partial effects in multivariate probit models with unobserved heterogeneity: An application to a discrete-time competing risk model, mimeo.

Cappellari, L., Dell'Aringa, C. and M. Leonardi (2011), Temporary Employment, Job Flows and Productivity: A Tale of two Reforms, CESIFO Working Paper, n. 3520.

Caroleo, F. E. (2012), The Hard Access to the Labour Market of Youth Leaving School: What Policy Choices?, MPRA Paper, No. 37645.

Caroleo, F. E. and F. Pastore (2007), The Youth Experience Gap: Explaining Differences across European Countries, Università di Perugia, Quaderni del Dipartimento di Economia, Finanza e Statistica, n. 41.

Caroleo, F.E. and F. Pastore (2009), Le cause del(l') (in)successo lavorativo dei giovani, Economia \& Lavoro, anno XLIII, n. 3, sett-dic.: 107-131.

Clark, K. B. and L. H. Summers (1982), Labour force participation: timing and persistence, Review of Economic Studies, 49(5): 825-844.

Contini, B. , Pacelli, L. and C. Villosio (2004), Stepping-Stones or Traps?: The Consequences of Labour Market Entry Positions on Future Careers in West Germany, Great Britain and Italy, Work, Employment \& Society, n. 18: 369-394.

D'Addio, A. C. and M. Rosholm (2002), Left censoring in duration data: theory and application, Univeristy of AArhus, Department of Economics, Working Paper n. 2002-5.

D'Addio, A. C. and M. Rosholm (2005), Exits from temporary jobs in Europe: a competing risks analysis, Labour Economics, 12(4): 449-468.

Dolado, J.J., Garcìa-Serrano, C. and J.F. Jimeno (2002), Drawing lessons from the boom of temporary jobs in Spain, The Economic Journal, Vol. 112, Issue 480: F270-F295.

Elia, L. (2010), The pathway to permanent jobs: a time event analysis of young Italian workers, Università della Calabria, Dipartimento di Economia e Statistica Working Paper, n. 18.

Freeman, R. B. and D. A. Wise (eds.) (1982), The Youth Labour Market Problem: Its Nature, causes and Consequences, University of Chicago Press, Chicago.

Gagliarducci, S. (2005), The dynamics of repeated temporary jobs, Labour Economics, 12(4): 429448.

Garcìa-Pérez, J. I. and F. Muñoz-Bullòn (2007), Transitions into permanent employment in Spain: an Empirical Analysis for Young Workers, Universidad Carlos III de Madrid, Business Economics Series Working Paper, n. 38.

Garrouste, C. and M. Loi (2011), School-to-work Transitions in Europe: Paths towards a Permanent Contract, MPRA working paper, n. 37167.

Gianmatteo, M., Mandrone E. and M. Tancioni (2012), Dinamiche di transizione ed esiti lavorativi. Dimensioni e caratteri del lavoro non-standard, Economia e Lavoro, 2: 79-103. 
Goos M., Manning A. and A. Solomons (2010), Explaining job polarization in Europe: The roles of technology, globalization and institutions, CEP Discussion Paper n. 1026.

Güell, M. and B. Petrongolo (2007), How binding are legal limits? Transitions from temporary to permanent work in Spain, Labour Economics, 14: 153-183

Hagen T. (2003), Do Fixed-term Contracts Increase the Long-term Employment Opportunities of the Unemployed?, ZEW Discussion Paper, n. 03-49.

Harslof, I. (2003), Processes of Marginalisation at Work - Integration of Young People in the Labour Market through Temporary Employment, in T. Hammer (ed.), Youth Unemployment and social Exclusion in Europe, Policy Press, Bristol.

Hartman, L., Liljeberg L. and O. Nordström Skans (2010), Stepping-stones, dead-ends, or both? An analysis of Swedish replacement contracts, Empirical Economics, 38: 645-668.

Heckman, J.J. and G.J. Borjas (1980), Does Unemployment Cause Future Unemployment? Definitions, Questions and Answers from a Continuous Time Model of Heterogeneity and State Dependence, Economica, 47(187): 247-283.

Heckman, J. J. and B. Singer (1984), A Method of Minimizing the Impact of Distributional Assumptions for Duration Data, Econometrica, 52: 271-320.

Heinrich, C. J., Mueser, P. R. and K. R. Troske (2009), The Role of Temporary Help Employment in Low-Wage Worker, in D. H. Autor (ed), Studies of Labor Market Intermediation, NBER Publication University of Chicago Press, Chicago: 399 - 436.

Holmlund, B. and D. Storrie (2002), Temporary Work in Turbulent Times: The Swedish Experience, The Economic Journal, Vol. 112, Issue 480: F245-F269.

Hotchkiss, J. (1999), The Effect of Transitional Employment on Search Duration: a Selectivity Approach, Atlantic Economic Journal, 27(1): 38-52.

Ichino, A., F. Mealli and T. Nannicini (2005), Temporary Work Agencies in Italy: A Springboard toward Permanent Employment?, Giornale degli Economisti e Annali di Economia, 64(1): 1-27.

Jenkins, S. P. (2005), Survival analysis, mimeo.

Kvasnicka, M. (2008), Does Temporary Help Work Provide a Stepping Stone to Regular Employment?, NBER Working Paper, n. 13843.

Loh, E., (1994), Employment probation as a sorting mechanism, ILR Review, 47(3): 471-486.

Magnac, T. (2000), Subsidised training and youth employment: distinguishing unobserved heterogeneity from state dependence in labour market histories, The Economic Journal, 110 (October): 805-837.

Mandrone, E. and M. Marocco (2012), Atipicità, flessibilità e precarietà: una lettura economica e giuridica attraverso l'indagine ISFOL-plus, Isfol Working Paper, http://isfoloa.isfol.it/handle/123456789/215.

Nunziata, L. and S. Staffolani (2007), Short-term Contracts Regulations and Dynamic Labour Demand: Theory and Evidence, Scottish Journal of Political Economy, Vol. 54, Issue 1: 72-104. 
Ochel, W. (2009), "The Political Economy of Two-tier Reforms of Employment Protection in Europe", International Journal of Labour Law and Industrial Relations, 25 (3): 237-260.

OECD (1994), The OECD Jobs Study, OECD, Paris.

OECD (2002), Taking the Measure of Temporary Employment, Employment Outlook, OECD, Paris.

OECD (2004), Employment Protection Regulation and Labor Market Performance, Employment Outlook, OECD, Paris.

OECD (2008), Off to a Good Start? Youth Labour Market Transitions in OECD Countries, Employment Outlook, OECD, Paris.

O'Higgins, N. (2010), The Impact of the Economic and Financial Crisis on Youth Employment: Measures for Labour Market Recovery in the European Union, Canada and the United States, ILO, Employment Working Paper, n. 70.

Pavlopoulos, D. (2009), Starting your Career with a Temporary Job: Stepping Stone or Dead-end?, SOEP papers, n. 228.

Picchio, M. (2008), Temporary Contracts and Transitions to stable Jobs in Italy, Labour, 22 s1(06), Special Issue:147-174.

Portugal, P. and J. Varejäo (2010), The Hidden Side of Temporary Employment: Fixed-term Contracts as a Screening Device, Banco de Portugal, Estudios e Documentos de Trabalho, Working paper, n. 29.

Quintini, G. and S. Martin (2006), Starting Well or Losing their Way? The Position of Youth in the Labour Market in OECD Countries, OECD Social Employment and Migration Working Paper, n. 29.

Quintini, G., Martin J.P. and S. Martin (2007), The Changing Nature of the School-to-Work Transition Process in OECD Countries, IZA discussion paper, n. 2582.

Rees, A. (1986), An Essay on Youth Joblessness, Journal of Economic Literature, 24(2): 613-628.

Righi, A. and D. Sciulli (2009), The Timing of the School-to-permanent Work Transition: A Comparison across Ten European Countries, Università di Perugia, Dipartimento di Economia, Finanza e Statistica, Quaderno n. 65.

Scherer, S. (1999), Early career patterns: a comparison of Great Britain and West Germany, MZES Working Paper, n.7.

Topel, R.H. and M.P. Ward (1992), Job Mobility and the Careers of Young Men, Quarterly Journal of Economics, 107(2): 439-479.

Verhofstadt, E. and C. Goebel (2008), "Is Temporary Employment a Stepping Stone for Unemployed School Leavers?," ZEW Discussion Papers, n. 093.

Zijl, M., van den Berg, G. J. and A. Heyma (2011), Stepping Stones for the Unemployed: The Effect of Temporary Jobs on the Duration until (Regular) Work, Journal of Population Economics, 24:107-139. 
Wang, R. and R. Weiss (1998), Probation, layoffs, and wage-tenure profiles: a sorting explanation, Labour Economics, 5(3): 359-383.

Wooldridge, J. M. (2010). Econometric Analysis of Cross Sections and Panel Data. Cambridge: The MIT Press. 


\section{Appendix 1}

The Italian part of the EU-SILC 2004-2007 panel used in this study is the so-called IT-SILC. The survey is an integrated design with 4 groups. This implies that every year a new group is added and one of the old ones is eliminated after 4 observations. Since we work with the first 4 waves of the survey, we do not observe the elimination of any of the original groups, but only the annual inclusion of each new group in the panel ${ }^{15}$. For this reason, in 2004 we observe 13,335 individuals, Group 1, then the sample doubles in 2005 with the inclusion of new 13,618 subjects, Group 2, and triplicates in 2006 when Group 3 of 13,565 persons is included. Between 2006 and 2007 the sample is kept stable to 41,310 individuals. Some people are lost for attrition in the follow-up. Therefore, at the end of our observation period, in 2007 , we observe at least the $21 \%$ of the sample ( 8,761 individuals belonging to the first group) for 4 consecutive periods, the maximum time span in which each group can stay in the sample before being substituted. The $26 \%$ of the total sample (11,065 individuals of the second group) is observed for 3 consecutive periods, and about the $32 \%$ of the 2007 sample $(15,277$ of those belonging to third group, entered in 2006) is followed for 2 consecutive periods. The remaining observations correspond to people observed only once between 2004 and 2007.

Our unrestricted sample contains four years, 2004-2007. But, on restructuring the data to pick out TE entrants as explained in Section 3 we lose the 2004 wave for the individuals in Group 1. Similarly, the 2005 and 2006 waves are lost for Groups 2 and 3, respectively. As a result, the estimation sample contains non-censored durations up to two years. Considering also censored durations, the longest spell in the data lasts up to three years. Specifically, individuals in Group 1 contribute with uncensored spells of 1 and 2 years and censored 3-year spells; those in Group 2 with uncensored 1-year and censored 2-year spells; and finally those in Group 3 with censored 1-year spells.

We assume that conditional on $z$, the process allocating individuals into groups is independent from the process generating the duration data. In other words, individual durations in TE are conditionally independent from the numbers of years individuals stay in the sample after entering TE. This assumption seems plausible, considering the rotating nature of the panel, which randomly assigns individuals to Group 1, 2 or 3 (Bover et al. (2002)).

Given the above considerations and the general formula for the likelihood function reported in Section 3 of the paper, the likelihood contribution of an individual in Group 1 specializes to

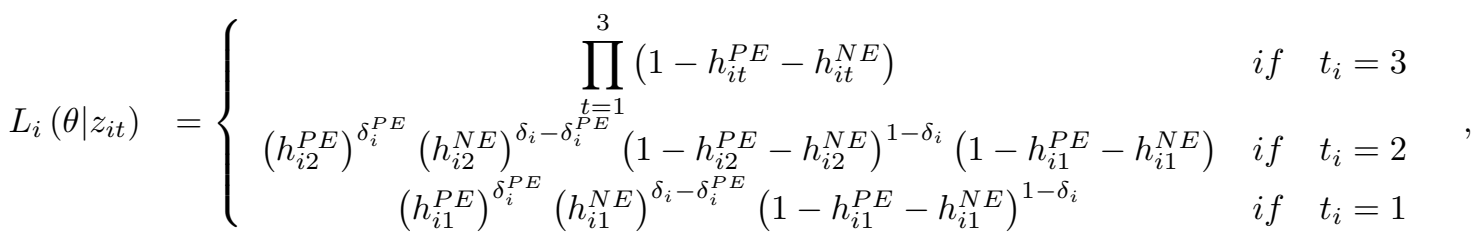

\footnotetext{
${ }^{15}$ After 2007 , Group 1 will be eliminated and substituted by a new one, and in the same way the other groups will be rotated over the following years.
} 
that of individuals in Group 2 is

$$
L_{i}\left(\theta \mid z_{i t}\right)=\left\{\begin{array}{cc}
\prod_{t=1}^{2}\left(1-h_{i t}^{P E}-h_{i t}^{N E}\right) & \text { if } \quad t_{i}=2 \\
\left(h_{i 1}^{P E}\right)^{\delta_{i}^{P E}}\left(h_{i 1}^{N E}\right)^{\delta_{i}-\delta_{i}^{P E}}\left(1-h_{i 1}^{P E}-h_{i 1}^{N E}\right)^{1-\delta_{i}} & \text { if } \quad t_{i}=1
\end{array},\right.
$$

and finally all individuals in Group 3 contribute with

$$
L_{i}\left(\theta \mid z_{i t}\right)=1-h_{i 1}^{P E}-h_{i 1}^{N E} .
$$

The log-likelihood function (LF) to be maximized is

$$
\log L(\theta \mid z) \equiv \sum_{i=1}^{N} \log L_{i}\left(\theta \mid z_{i t}\right)
$$


Fig. 1 Share of temporary employees over total employees

OECD Countries

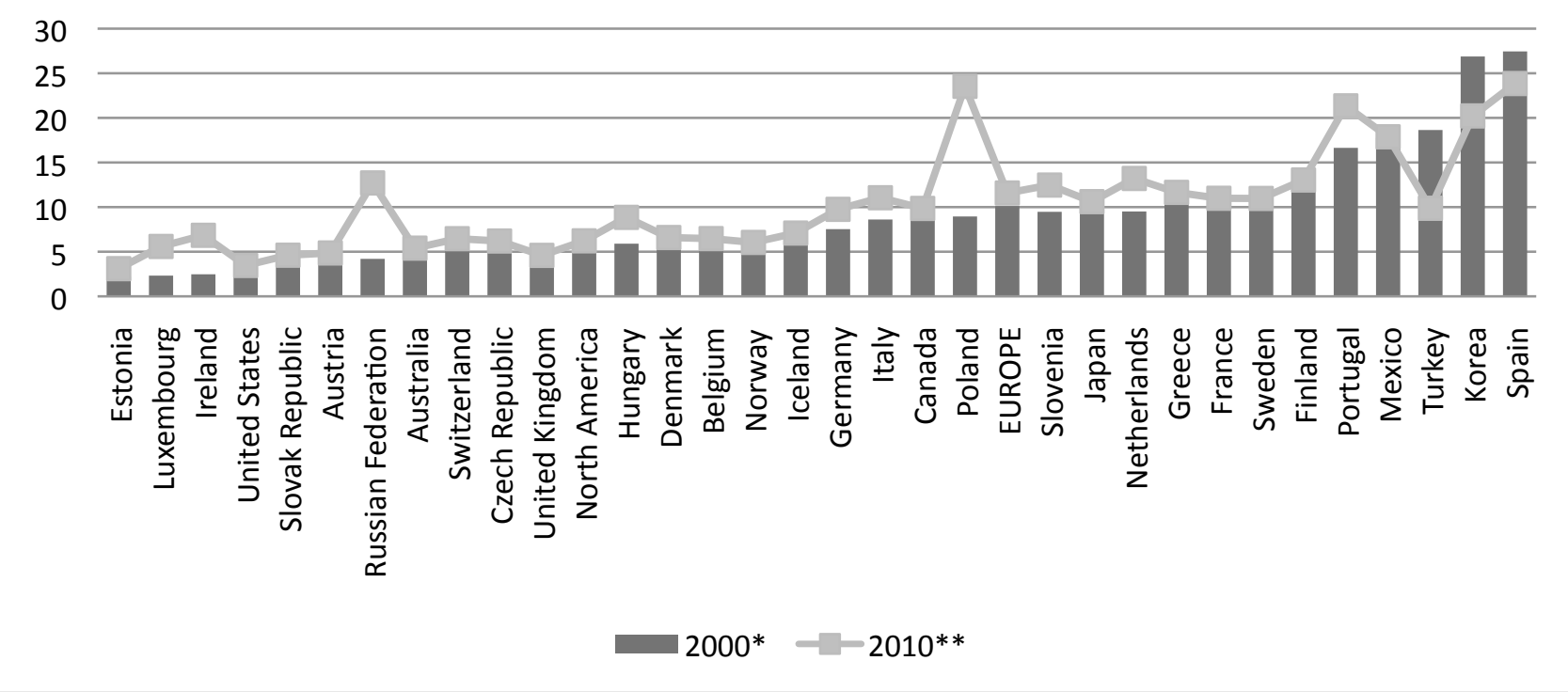

* Australia 2001, Korea 2004, Poland 2001, Slovenia 2002, United States 2001, Estonia 2002

** Australia 2006, Iceland 2009, Mexico 2004, United States 2005, Russia Federation 2008

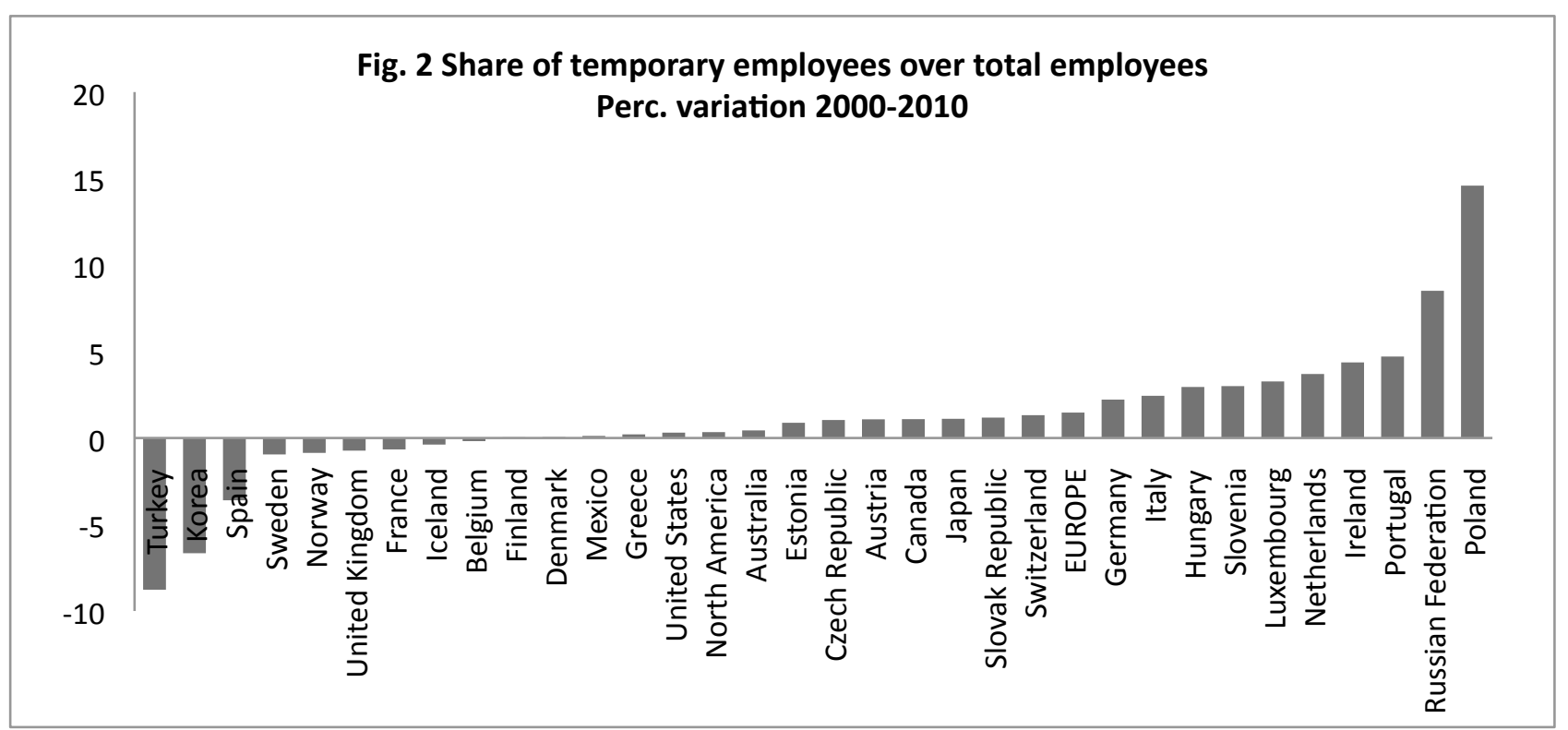


Fig. 3 Share of temporary employees over employees aged 15-24 OECD Countries

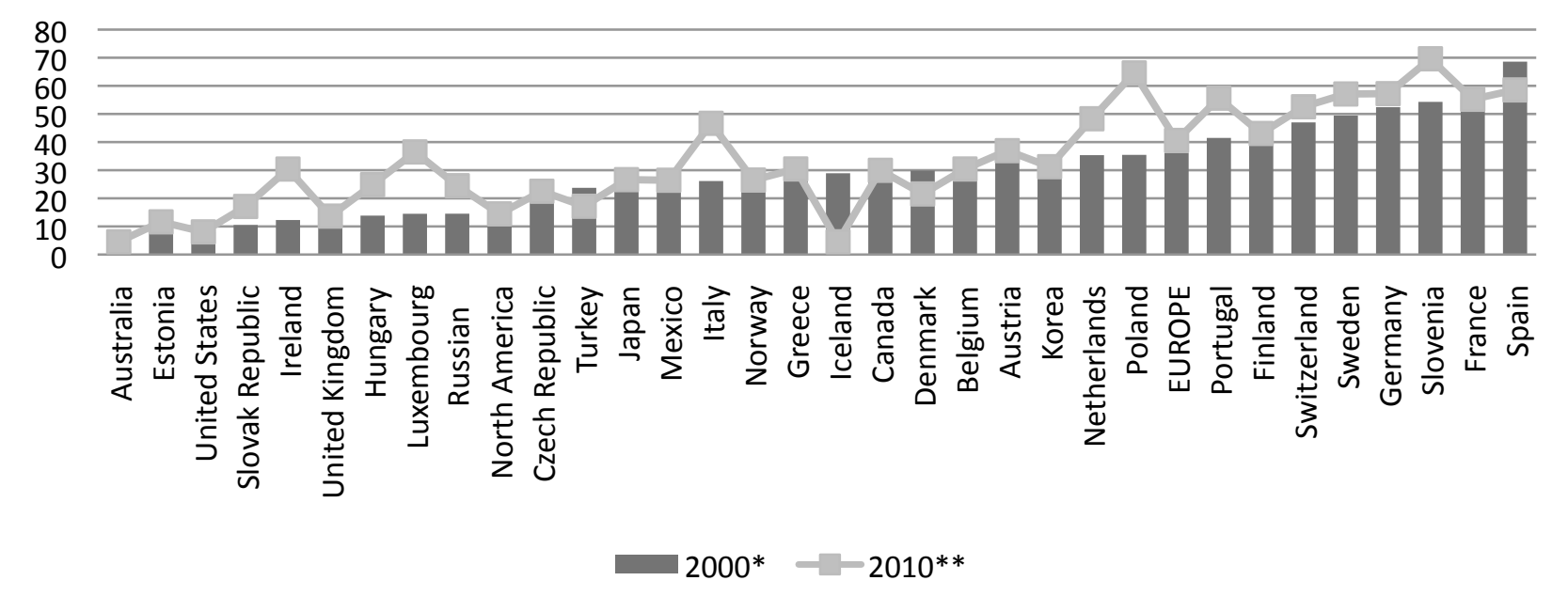

* Australia 2001, Korea 2004, Poland 2001, Slovenia 2002, United States 2001, Estonia 2002

** Australia 2006, Iceland 2009, Mexico 2004, United States 2005, Russia Federation 2008

Fig. 4 Share of temporary employees over employees aged 15-24 Perc. variation 2000-2010

40

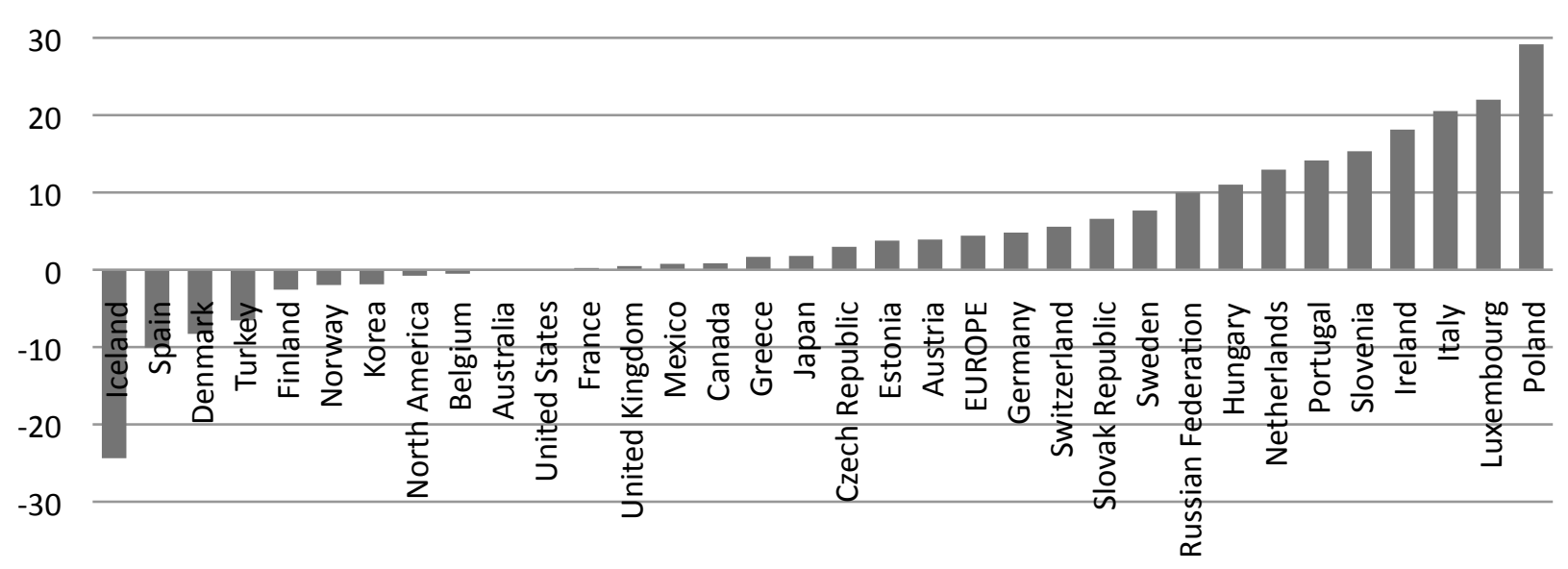


Tab. 1 Average of yearly transitions from temporary employment between 2004 and 2007.

\begin{tabular}{|l|l|l|l|l|l|l|l|l|l|}
\hline \multicolumn{4}{|l|}{ All } & \multicolumn{4}{l}{ Men } & \multicolumn{3}{l|}{ Women } \\
\hline Age 16-66 & TE & PE & NE & TE & PE & NE & TE & PE & NE \\
\hline TE & 52.41 & 31.26 & 16.33 & 49.63 & 34.77 & 15.61 & 54.83 & 28.22 & 16.95 \\
\hline Total & 6.23 & 50.3 & 43.47 & 6.19 & 63.05 & 30.76 & 6.26 & 39.63 & 54.11 \\
\hline Age 16-25 & & & & & & & & & \\
\hline TE & 49.64 & 32.61 & 17.75 & 49.5 & 34.11 & 16.39 & 49.8 & 30.83 & 19.37 \\
\hline Total & 15.63 & 52.24 & 32.13 & 15.04 & 57.02 & 27.93 & 16.29 & 46.82 & 36.89 \\
\hline Age 26-39 & & & & & & & & & \\
\hline TE & 53.68 & 32.23 & 14.09 & 51.42 & 36.38 & 12.2 & 55.34 & 29.19 & 15.47 \\
\hline Total & 9.27 & 63.98 & 26.75 & 8.57 & 79.22 & 12.22 & 9.86 & 51.23 & 38.92 \\
\hline Age 40-66 & & & & & & & & & \\
\hline TE & 52.63 & 28.57 & 18.8 & 47.12 & 33.01 & 19.87 & 57.51 & 24.65 & 17.85 \\
\hline Total & 3.07 & 42.76 & 54.16 & 3.15 & 55.47 & 41.38 & 3.02 & 32.65 & 64.33 \\
\hline
\end{tabular}

Source: IT-SILC 2004-2007

Tab. 2 Patterns of durations in the estimation sample.

\begin{tabular}{|l|c|c|c|r|}
\hline \multicolumn{5}{|c|}{ Spell length } \\
\hline & $\mathrm{t}=3$ & $\mathrm{t}=2$ & $\mathrm{t}=1$ & Total \\
\hline N. spells & 30 & 208 & 934 & 1172 \\
\hline$\%$ & 2.56 & 17.75 & 79.69 & 100 \\
\hline
\end{tabular}


Tab. 3 Descriptive statistics of the explanatory variables used for regressions.

\begin{tabular}{|c|c|c|c|c|}
\hline Variable & Mean & Std. Dev. & Min & Max \\
\hline Males & 0.4618056 & 0.4987122 & 0 & 1 \\
\hline Females & 0.5381944 & 0.4987122 & 0 & 1 \\
\hline Age & 34.03056 & 10.71777 & 18 & 67 \\
\hline Age2 & 1272.869 & 805.9792 & 324 & 4489 \\
\hline NE previous period & 0.4256944 & 0.4946196 & 0 & 1 \\
\hline School leaver & 0.0598007 & 0.2372486 & 0 & 1 \\
\hline dur1 & 0.8090278 & 0.3932038 & 0 & 1 \\
\hline dur2 & 0.1701389 & 0.3758853 & 0 & 1 \\
\hline dur3 & 0.0208333 & 0.1428758 & 0 & 1 \\
\hline Ever married & 0.44375 & 0.4969985 & 0 & 1 \\
\hline Education primary & 0.06875 & 0.2531164 & 0 & 1 \\
\hline Education secondary & 0.76875 & 0.4217784 & 0 & 1 \\
\hline Education tertiary & 0.1625 & 0.369037 & 0 & 1 \\
\hline Experience & 10.36944 & 9.059277 & 1 & 46 \\
\hline Occupation H skill & 0.2854167 & 0.4517695 & 0 & 1 \\
\hline Occupation M skill & 0.3444444 & 0.4753519 & 0 & 1 \\
\hline Occupation L skill & 0.3701389 & 0.4830094 & 0 & 1 \\
\hline Full time & 0.7395833 & 0.4390144 & 0 & 1 \\
\hline Part time & 0.2604167 & 0.4390144 & 0 & 1 \\
\hline Children less 12 & 0.2986111 & 0.4578079 & 0 & 1 \\
\hline Year of birth & 1972.32 & 10.73023 & 1940 & 1988 \\
\hline North-East & 0.1701389 & 0.3758853 & 0 & 1 \\
\hline Noerth-West & 0.2277778 & 0.4195442 & 0 & 1 \\
\hline Centre & 0.2361111 & 0.4248388 & 0 & 1 \\
\hline South & 0.2729167 & 0.4456131 & 0 & 1 \\
\hline Islands & 0.0930556 & 0.2906112 & 0 & 1 \\
\hline Health bad & 0.0284722 & 0.1663754 & 0 & 1 \\
\hline Health good & 0.9715278 & 0.1663754 & 0 & 1 \\
\hline Income & 8302.631 & 6833.288 & 0 & 49346 \\
\hline Benefits & 0.0444444 & 0.206152 & 0 & 1 \\
\hline Unemployment & 7.135972 & 3.66869 & 3.1 & 15.3 \\
\hline Growth & 1.429552 & .6629647 & -0.1875401 & 2.828836 \\
\hline
\end{tabular}


Tab. 4 Marginal effects for the estimation sample.

\begin{tabular}{|c|c|c|c|c|c|c|c|c|c|c|c|c|c|c|c|c|c|c|}
\hline MARGINALS & & & & & & & & & & & & & & & & & & \\
\hline & ALL & & & & & & MEN & & & & & & WOMEN & & & & & \\
\hline & $\mathrm{TE}$ & & $\mathrm{PE}$ & & $\mathrm{NE}$ & & $\mathrm{TE}$ & & $\mathrm{PE}$ & & $\mathrm{NE}$ & & $\mathrm{TE}$ & & $\mathrm{PE}$ & & $\mathrm{NE}$ & \\
\hline $\mathrm{d} 1$ & 1.747 & $* * *$ & -1.094 & $* * *$ & -0.653 & $* * *$ & 1.994 & $* * *$ & -1.327 & $* * *$ & -0.667 & $* * *$ & 1.618 & $* * *$ & -1.059 & $* * *$ & -0.559 & $* * *$ \\
\hline $\mathrm{d} 2$ & 1.760 & $* * *$ & -1.028 & $* * *$ & -0.732 & $* * *$ & 1.977 & $* * *$ & -1.187 & $* * *$ & -0.790 & $* * *$ & 1.661 & $* * *$ & -1.055 & $* * *$ & -0.606 & $* * *$ \\
\hline $\mathrm{d} 3$ & 3.725 & $* * *$ & -2.310 & $* * *$ & -1.414 & $* * *$ & 3.871 & $* * *$ & -2.563 & $* * *$ & -1.308 & $* * *$ & 3.372 & $* * *$ & -2.058 & $* * *$ & -1.314 & $* * *$ \\
\hline Women & 0.016 & & -0.035 & $*$ & 0.018 & & & & & & & & & & & & & \\
\hline NE precedent & 0.012 & & -0.041 & $* *$ & 0.029 & $*$ & 0.000 & & -0.026 & & 0.026 & & 0.020 & & -0.046 & $* *$ & 0.027 & \\
\hline School leavers & 0.022 & & -0.055 & $*$ & 0.033 & & 0.017 & & -0.054 & & 0.037 & & 0.037 & & -0.056 & & 0.019 & \\
\hline Age & 0.001 & & -0.001 & & 0.000 & & 0.000 & & -0.002 & & 0.001 & & 0.000 & & 0.000 & & 0.000 & \\
\hline North-West & 0.069 & $* *$ & -0.052 & $* *$ & -0.017 & & 0.080 & $*$ & -0.083 & $* *$ & 0.004 & & 0.062 & & -0.034 & & -0.028 & \\
\hline Centre & 0.614 & $* * *$ & -0.405 & $* * *$ & -0.209 & $* * *$ & 0.669 & $* * *$ & -0.477 & $* * *$ & -0.191 & $* * *$ & 0.568 & $* * *$ & -0.360 & $* * *$ & -0.209 & $* * *$ \\
\hline South & 2.259 & $* * *$ & -1.470 & $* * *$ & -0.789 & $* * *$ & 2.598 & $* * *$ & -1.908 & $* * *$ & -0.690 & $* * *$ & 1.994 & $* * *$ & -1.159 & $* * *$ & -0.835 & $* * *$ \\
\hline Islands & 2.448 & $* * *$ & -1.603 & *** & -0.845 & $* * *$ & 2.708 & $* * *$ & -1.999 & $* * *$ & -0.709 & $* * *$ & 2.270 & $* * *$ & -1.327 & $* * *$ & -0.942 & *** \\
\hline Health bad & 0.063 & & -0.028 & & -0.034 & & -0.020 & & 0.055 & & -0.035 & & 1.086 & $* * *$ & -1.265 & $* * *$ & 0.180 & $* *$ \\
\hline Children less 12 & 0.052 & ** & -0.015 & & -0.037 & $* *$ & 0.040 & & 0.015 & & -0.055 & ** & 0.055 & * & -0.037 & & -0.018 & \\
\hline Education 2 & 0.005 & & 0.037 & & -0.042 & & 0.065 & & 0.006 & & -0.071 & ** & -0.092 & & 0.074 & & 0.018 & \\
\hline Education 3 & 0.008 & & 0.033 & & -0.041 & & 0.077 & & 0.010 & & -0.087 & & -0.085 & & 0.059 & & 0.025 & \\
\hline Occupation M-skill & -0.045 & $*$ & 0.017 & & 0.027 & & -0.009 & & -0.002 & & 0.010 & & -0.047 & & 0.017 & & 0.030 & \\
\hline Occupation L-skill & -0.070 & ** & 0.013 & & 0.057 & $* * *$ & -0.054 & & 0.009 & & 0.046 & & -0.068 & $*$ & 0.003 & & 0.064 & $* *$ \\
\hline Part-time & 0.021 & & -0.003 & & -0.019 & & 0.001 & & -0.022 & & 0.021 & & 0.038 & & 0.002 & & -0.040 & $*$ \\
\hline Income & 0.000 & & 0.000 & & 0.000 & $* *$ & 0.000 & & 0.000 & & 0.000 & $*$ & & & 0.000 & & 0.000 & \\
\hline Experience & -0.002 & & 0.002 & & -0.001 & & -0.002 & & 0.003 & & -0.001 & & & & 0.002 & & -0.001 & \\
\hline Benefits & -0.059 & & 0.049 & & 0.010 & & -0.009 & & 0.014 & & -0.005 & & -0.104 & $*$ & 0.069 & & 0.035 & \\
\hline Unemployment & -0.275 & $* * *$ & 0.175 & $* * *$ & 0.100 & $* * *$ & -0.310 & $* * *$ & 0.223 & $* * *$ & 0.087 & $* * *$ & -0.248 & $* * *$ & 0.140 & $* * *$ & 0.108 & $* * *$ \\
\hline Growth & -0.118 & $* * *$ & 0.058 & $* * *$ & 0.060 & $* * *$ & -0.166 & $* * *$ & 0.089 & $* * *$ & 0.076 & $* * *$ & -0.075 & $* *$ & 0.033 & & 0.042 & $* *$ \\
\hline
\end{tabular}

Levels of significance: $* 10 \%-5 \%$; ${ }^{*} 5 \%-1 \%$; $* *$ less than $1 \%$ 
Tab. 5 Empirical and estimated hazards: Men subsample.

\begin{tabular}{|c|c|c|c|c|c|}
\hline & & Hazard to PE & & Hazard to NE & \\
\hline & Years & Empirical & Estimateda & Empirical & Estimated \\
\hline \multirow[t]{4}{*}{ All } & 1 & 0.140 & & 0.091 & \\
\hline & & $(0.111,0.169)$ & & $(0.067,0.115)$ & \\
\hline & 2 & 0.236 & & 0.009 & \\
\hline & & $(0.154,0.318)$ & & $(-0.009,0.028)$ & \\
\hline \multirow[t]{4}{*}{ South \& Isles } & 1 & 0.110 & 0.119 & 0.089 & 0.092 \\
\hline & & $(0.070,0.150)$ & & $(0.052,0.126)$ & \\
\hline & 2 & 0.167 & 0.117 & 0.024 & 0.008 \\
\hline & & $(0.049,0.284)$ & & $(-0.024,0.072)$ & \\
\hline \multirow[t]{4}{*}{ North \& Centre } & 1 & 0.162 & 0.156 & 0.092 & 0.090 \\
\hline & & $(0.121,0.203)$ & & $(0.060,0.125)$ & \\
\hline & 2 & 0.281 & 0.314 & 0 & 0.010 \\
\hline & & $(0.168,0.394)$ & & $(64)^{b}$ & \\
\hline \multirow[t]{4}{*}{ Age $<30$} & 1 & 0.124 & 0.132 & 0.091 & 0.086 \\
\hline & & $(0.084,0.163)$ & & $(0.057,0.125)$ & \\
\hline & 2 & 0.228 & 0.237 & 0 & 0.008 \\
\hline & & $(0.116,0.340)$ & & (57) & \\
\hline \multirow[t]{4}{*}{ Age $\geq 30$} & 1 & 0.156 & 0.148 & 0.091 & 0.096 \\
\hline & & $(0.113,0.200)$ & & $(0.057,0.125)$ & \\
\hline & 2 & 0.245 & 0.234 & 0.020 & 0.011 \\
\hline & & $(0.120,0.370)$ & & $(-0.021,0.061)$ & \\
\hline \multirow[t]{4}{*}{ School leavers } & 1 & 0.090 & 0.093 & 0.115 & 0.113 \\
\hline & & $(0.025,0.155)$ & & $(0.043,0.188)$ & \\
\hline & 2 & 0.150 & 0.138 & 0 & 0.010 \\
\hline & & $(-0.021,0.321)$ & & (20) & \\
\hline
\end{tabular}

a Since an exhaustive set of dummies is included, empirical and estimated hazards coincide for the whole sample.

b 95\% asymptotic confidence intervals for the empirical hazards are in parentheses, except when the empirical hazard is exactly 0 , in which case the relavant sub sample size is reported. 
Tab. 6 Empirical and estimated hazards: Women subsample.

\begin{tabular}{|c|c|c|c|c|c|}
\hline & & Hazard to PE & & Hazard to NE & \\
\hline & Years & Empirical & Estimated $^{\mathrm{a}}$ & Empirical & Estimated \\
\hline \multirow[t]{4}{*}{ All } & 1 & 0.130 & & 0.115 & \\
\hline & & $(0.103,0.157)$ & & $(0.090,0.141)$ & \\
\hline & 2 & 0.079 & & 0.036 & \\
\hline & & $(0.034,0.125)$ & & $(0.005,0.067)$ & \\
\hline \multirow[t]{4}{*}{ South \& Isles } & 1 & 0.124 & 0.132 & 0.154 & 0.154 \\
\hline & & $(0.078,0.170)$ & & $(0.104,0.205)$ & \\
\hline & 2 & 0.075 & 0.038 & 0.025 & 0.025 \\
\hline & & $(-0.010,0.160)$ & & $(-0.026,0.076)$ & \\
\hline \multirow[t]{4}{*}{ North \& Centre } & 1 & 0.133 & 0.129 & 0.097 & 0.097 \\
\hline & & $(0.100,0.166)$ & & $(0.068,0.125)$ & \\
\hline & 2 & 0.081 & 0.096 & 0.040 & 0.040 \\
\hline & & $(0.026,0.135)$ & & $(0.001,0.080)$ & \\
\hline \multirow[t]{4}{*}{ Age $<30$} & 1 & 0.107 & 0.108 & 0.120 & 0.115 \\
\hline & & $(0.072,0.142)$ & & $(0.083,0.158)$ & \\
\hline & 2 & 0.059 & 0.071 & 0.015 & 0.037 \\
\hline & & $(0.001,0.116)$ & & $(-0.015,0.044)$ & \\
\hline \multirow[t]{4}{*}{ Age $\geq 30$} & 1 & 0.152 & 0.151 & 0.111 & 0.116 \\
\hline & & $(0.112,0.192)$ & & $(0.076,0.146)$ & \\
\hline & 2 & 0.099 & 0.087 & 0.056 & 0.035 \\
\hline & & $(0.028,0.170)$ & & $(0.001,0.111)$ & \\
\hline \multirow[t]{4}{*}{ School leavers } & 1 & 0.091 & 0.095 & 0.131 & 0.122 \\
\hline & & $(0.033,0.149)$ & & $(0.064,0.199)$ & \\
\hline & 2 & 0.067 & 0.053 & 0 & 0.031 \\
\hline & & $(-0.028,0.161)$ & & $(30)^{b}$ & \\
\hline
\end{tabular}

a Since an exhaustive set of dummies is included, empirical and estimated hazards coincide for the whole sample.

b 95\% asymptotic confidence intervals for the empirical hazards are in parentheses, except when the empirical hazard is exactly 0 , in which case the relavant sub sample size is reported. 